University of Wollongong

Research Online

Faculty of Social Sciences - Papers (Archive) Faculty of Arts, Social Sciences \& Humanities

$1-1-2016$

Acute and chronic effects of cannabinoids on human cognition-a systematic review

\author{
Samantha J. Broyd \\ University of Wollongong, sbroyd@uow.edu.au \\ Hendrika $\mathrm{H}$. van Hell \\ University of Wollongong, erikavh@uow.edu.au \\ Camilla Beale \\ University of Wollongong, cb993@uowmail.edu.au \\ Murat Yucel \\ University of Melbourne \\ Nadia Solowij \\ University of Wollongong, nadia@uow.edu.au
}

Follow this and additional works at: https://ro.uow.edu.au/sspapers

Part of the Education Commons, and the Social and Behavioral Sciences Commons 


\title{
Acute and chronic effects of cannabinoids on human cognition-a systematic review
}

\begin{abstract}
Cannabis use has been associated with impaired cognition during acute intoxication as well as in the unintoxicated state in long-term users. However, the evidence has been mixed and contested, and no systematic reviews of the literature on neuropsychological task-based measures of cognition have been conducted in an attempt to synthesize the findings. We systematically review the empirical research published in the past decade (from January 2004 to February 2015) on acute and chronic effects of cannabis and cannabinoids and on persistence or recovery after abstinence. We summarize the findings into the major categories of the cognitive domains investigated, considering sample characteristics and associations with various cannabis use parameters. Verbal learning and memory and attention are most consistently impaired by acute and chronic exposure to cannabis. Psychomotor function is most affected during acute intoxication, with some evidence for persistence in chronic users and after cessation of use. Impaired verbal memory, attention, and some executive functions may persist after prolonged abstinence, but persistence or recovery across all cognitive domains remains underresearched. Associations between poorer performance and a range of cannabis use parameters, including a younger age of onset, are frequently reported. Little further evidence has emerged for the development of tolerance to the acutely impairing effects of cannabis. Evidence for potential protection from harmful effects by cannabidiol continues to increase but is not definitive. In light of increasing trends toward legalization of cannabis, the knowledge gained from this body of research needs to be incorporated into strategies to minimize harm.
\end{abstract}

\section{Keywords}

review, systematic, cognition, chronic, human, acute, cannabinoids, effects

\section{Disciplines}

Education | Social and Behavioral Sciences

\section{Publication Details}

Broyd, S. J., van Hell, H. H., Beale, C., Yucel, M. \& Solowij, N. (2016). Acute and chronic effects of cannabinoids on human cognition-a systematic review. Biological Psychiatry, 79 (1), 557-567. 


\title{
Acute and Chronic Effects of Cannabinoids on Human Cognition-A Systematic Review
}

\author{
Samantha J. Broyd, Hendrika H. van Hell, Camilla Beale, Murat Yücel, and Nadia Solowij
}

\begin{abstract}
Cannabis use has been associated with impaired cognition during acute intoxication as well as in the unintoxicated state in long-term users. However, the evidence has been mixed and contested, and no systematic reviews of the literature on neuropsychological task-based measures of cognition have been conducted in an attempt to synthesize the findings. We systematically review the empirical research published in the past decade (from January 2004 to February 2015) on acute and chronic effects of cannabis and cannabinoids and on persistence or recovery after abstinence. We summarize the findings into the major categories of the cognitive domains investigated, considering sample characteristics and associations with various cannabis use parameters. Verbal learning and memory and attention are most consistently impaired by acute and chronic exposure to cannabis. Psychomotor function is most affected during acute intoxication, with some evidence for persistence in chronic users and after cessation of use. Impaired verbal memory, attention, and some executive functions may persist after prolonged abstinence, but persistence or recovery across all cognitive domains remains underresearched. Associations between poorer performance and a range of cannabis use parameters, including a younger age of onset, are frequently reported. Little further evidence has emerged for the development of tolerance to the acutely impairing effects of cannabis. Evidence for potential protection from harmful effects by cannabidiol continues to increase but is not definitive. In light of increasing trends toward legalization of cannabis, the knowledge gained from this body of research needs to be incorporated into strategies to minimize harm.
\end{abstract}

Keywords: Attention, Brain, Cannabis, Cognition, Executive function, Memory

http://dx.doi.org/10.1016/j.biopsych.2015.12.002

Shifts in public opinion and policies toward legalization of cannabis are poised to result in an increase in the prevalence of cannabis use beyond the 178 million users estimated to exist today (1-3). Although most individuals who try cannabis do not go on to use it regularly $(1,2)$, individuals who do so risk adverse effects to physical and mental health (4). Negative sequelae that have been attributed to regular and prolonged cannabis use include alterations to brain morphology (5-7) and function (8-11); psychosis risk (12,13); poor psychosocial outcomes $(4,14-17)$; and impaired cognition, especially deficits in attention, learning and memory (18-21), and executive functions $(9,22)$. Morphological and connectivity changes in brain structures with high amounts of cannabinoid receptors (e.g., hippocampus, prefrontal cortex, cerebellum) (23) may mediate observed cognitive deficits in cannabis users (5-7, 9-11,24), although direct structure/function relationships are not readily demonstrated.

A substantial number of studies have been published in recent years, prompted by renewed interest in understanding the effects of cannabis on the brain partly as a result of mounting evidence for links between cannabis use and psychosis (25-28) and recognition of similarities between cognitive impairment in cannabis users and deficits observed in patients with schizophrenia (19). Interest has emerged in examining the effects of different compounds within cannabis plant matter, specifically (-)-trans $-\Delta^{9}$-tetrahydrocannabinol (THC), the primary psychoactive constituent considered to be psychotogenic, and cannabidiol (CBD), the second most abundant cannabinoid, shown to have antipsychotic properties (29) and to attenuate the psychotogenic effects of THC, with opposite effects on brain function (30). Recent critical reviews have focused on neuroimaging outcomes from acute cannabinoid challenge $(9,31)$ and on brain morphology in chronic users $(5,7,32)$. However, to date, the literature on neuropsychological task-based measures of cognition has not been examined in the form of a systematic review. We systematically review the empirical research published in the past decade. We identify core themes that have emerged from the recent literature or continue to plague this field and study limitations and future directions for this research area.

\section{METHOD}

This systematic review was conducted in accordance with Preferred Reporting Items for Systematic Reviews and MetaAnalyses guidelines (Figure 1) (33). The search strategy and 


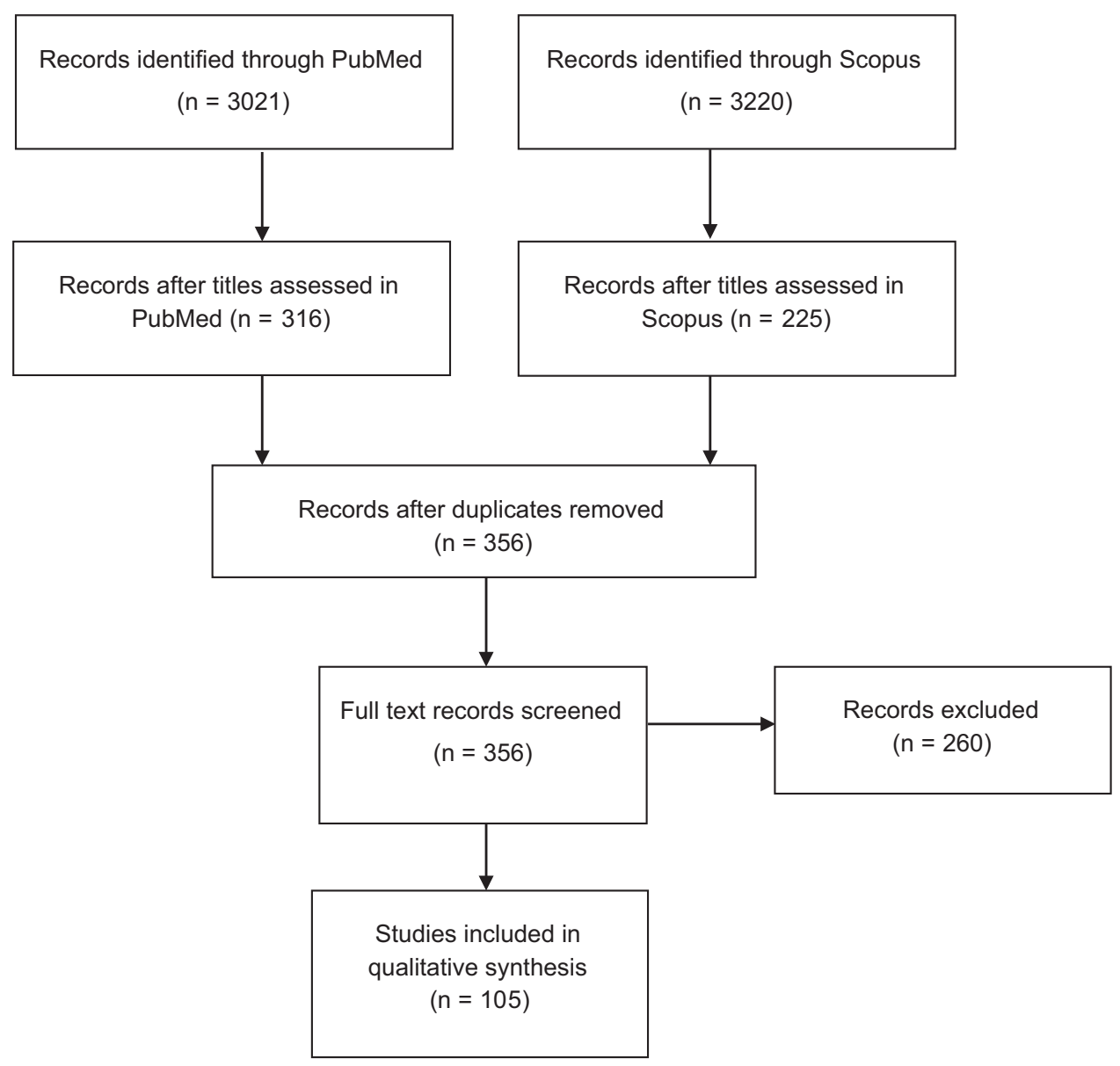

Figure 1. Preferred Reporting Items for Systematic Reviews and MetaAnalyses flow diagram for systematic search and identification of studies meeting inclusion criteria for systematic review. Selection criteria were as follows: 1) neuropsychological or cognitive experimental tasks administered to regular or former cannabis users or after acute administration of cannabis or synthetic or phytocannabinoid compounds; 2) cannabis (or cannabinoids) as the primary drug of interest; and 3) human participants. Exclusion criteria were as follows: 1) studies in which cannabis was not the primary drug of concern; 2) questionnaire (trait) measures of cognition; 3) major psychopathology or neurologic conditions within assessed sample; 4) animal research; 5) neuroimaging, electrophysiologic, or autonomic measures as primary outcome variables; 6) treatment (e.g., cognitivebehavioral therapy) as the primary focus; 7) real-world multiplex tasks requiring simultaneous use and integration of multiple aspects of cognition, such as driving; and 8) case studies.

data extraction are detailed in Supplement 1, and selection criteria, resulting in 105 studies included for review, are provided in the legend of Figure 1. From each study, we extracted participant demographics (age, sex, IQ), cannabis use metrics (e.g., age of onset and duration, frequency, and quantity of use), period of abstinence before testing, extent of other substance use (including alcohol and tobacco), dosing details for acute administration studies, cognitive domains investigated, experimental tasks employed, and key cognitive findings. The primary results of interest for qualitative synthesis of findings were group differences in performance and associations with cannabis use metrics.

\section{RESULTS}

We provide a summary appraisal of findings organized by primary cognitive domain in order of evidential strength from most to least consistently impaired. A more detailed account of findings from all studies is provided in Supplement 1, and detailed data extracted from each article are tabulated in Table S1 in Supplement 2. Within each cognitive domain, we address first acute administration studies, then studies of chronic exposure to cannabis, followed briefly by abstinence studies. Further consideration is given to the important issue of persistence or recovery of function separately in the
Discussion. Table 1 provides a qualitative summary of findings across all cognitive domains examined.

\section{Memory}

Memory function has been the most consistently impaired cognitive domain affected by cannabis, and studies from the past 10 years continue to extend the evidence base. The most extensive evidence for impairment is within verbal learning and memory.

Verbal Learning and Memory. Most often measured using word list learning tasks, with several immediate and delayed recall trials and a recognition trial, verbal learning and memory tasks have been identified as particularly sensitive to the acute $(20,34,35)$ and chronic (18) effects of cannabis. Further clear evidence has emerged for impairing effects of acute intravenous (IV) THC (36-40), vaporized cannabis $(41,42)$ and oral nabilone (43) on immediate and delayed recall and sometimes recognition accuracy. Predosing with $\mathrm{CBD}$ or greater CBD content in cannabis may protect against some THC-induced verbal learning and memory deficits $(40,44)$. Impaired verbal learning and memory continues to be consistently observed in chronic cannabis users, including adolescents (45-47) and young adults (48-52) [with some 
Table 1. Strength and Consistency of Evidence for Impairment Associated With Acute and Chronic Cannabis Use and for Recovery of Function With Abstinence From Research Published in the Past Decade

\begin{tabular}{|c|c|c|c|c|c|c|c|}
\hline \multirow[b]{2}{*}{ Cognitive Domain } & \multirow[b]{2}{*}{ Acute $^{b}$} & \multirow[b]{2}{*}{ Chronic $^{b}$} & \multirow{2}{*}{$\begin{array}{l}\text { Persistence } \\
\quad \text { With } \\
\text { Abstinence }^{b}\end{array}$} & \multirow[b]{2}{*}{$\begin{array}{c}\text { Pertinent Cannabis Use } \\
\text { Parameters }\end{array}$} & \multicolumn{3}{|c|}{ Number of Studies } \\
\hline & & & & & Acute & Chronic & Abstinence \\
\hline \multicolumn{8}{|l|}{ Memory } \\
\hline $\begin{array}{l}\text { Verbal learning and } \\
\text { memory }\end{array}$ & +++ & +++ & +- & $\begin{array}{l}\text { Frequency; lifetime use; } \\
\text { duration; age of onset; } \\
\text { sex }\end{array}$ & $11(36-44,77,87)$ & $20(44-58,60-62,66,142)$ & $9(55,57,60,63-67,95)$ \\
\hline Working memory & +- & +- & +- & $\begin{array}{l}\text { Frequency; lifetime use; } \\
\text { recency; sex }\end{array}$ & $20(36-40,42,43,68-78,88,143)$ & $\begin{array}{l}16(46,48,49,51-53,55,57 \\
\quad 79-84,115,119)\end{array}$ & $7(55,57,64,65,67,79,85)$ \\
\hline Other memory function & + & +- & - & $\begin{array}{l}\text { Age of onset; frequency; } \\
\text { recency }\end{array}$ & $2(42,144)$ & $8(45,49,78-80,119,144,145)$ & $4(63,65,79,95)$ \\
\hline \multicolumn{8}{|l|}{ Attention } \\
\hline Attention & +++ & +++ & +- & $\begin{array}{l}\text { Dose; age of onset; length } \\
\text { of abstinence; } \\
\text { withdrawal effects }\end{array}$ & $\begin{array}{l}16(36,37,39,42,43,68,70,71,76,77, \\
86-90,143)\end{array}$ & $\begin{array}{l}14(45,46,54,55,57,61,79-81,84, \\
\quad 91-94)\end{array}$ & $\begin{array}{l}10(55,57,63,64,67,79,91- \\
\quad 93,95)\end{array}$ \\
\hline Attentional bias & + & +++ & NA & $\begin{array}{l}\text { Craving; dependence; } \\
\text { frequency; CBD }\end{array}$ & $1(102)$ & $7(96-102)$ & None \\
\hline Psychomotor Function & +++ & + & + & & $\begin{array}{l}18(37,42,43,68,70,73,74,76,77,89,90 \\
\quad 103-107,143,146)\end{array}$ & $10(46,48,51,54,57,66,78,80,91,108)$ & $6(57,63-65,67,91)$ \\
\hline \multicolumn{8}{|l|}{ Executive Function } \\
\hline $\begin{array}{l}\text { Planning, reasoning, } \\
\text { interference control, } \\
\text { and problem solving }\end{array}$ & +- & +- & +- & $\begin{array}{l}\text { Neurodevelopmental stage; } \\
\text { age of onset; frequency }\end{array}$ & $12(37-41,77,86,89,103,104,106,109)$ & $\begin{array}{c}23(46,48,52-54,57,60,61,66,78 \\
81-84,93,98,110-115,147)\end{array}$ & $\begin{array}{l}9(57,60,63- \\
\quad 65,67,85,93,95)\end{array}$ \\
\hline Inhibition & ++ & +- & NA & Frequency; task complexity & $5(42,89,103,104,109)$ & $9(45,50,54,56,82,110,116-118)$ & None \\
\hline Verbal fluency & - & +- & +- & & $3(36,38,44)$ & $6(44,48,51,53,54,61)$ & $4(65,67,93,119)$ \\
\hline Time estimation & +- & - & - & & $6(73,74,77,86,148,149)$ & $1(55)$ & $1(55)$ \\
\hline Decision Making & +- & +- & - & $\begin{array}{l}\text { Age of onset; lifetime } \\
\text { exposure; frequency; } \\
\text { cannabis use disorder }\end{array}$ & $7(103,105,106,109,120-122)$ & $\begin{array}{l}17(45,48,50,56,78,82,84,94,113,116 \\
\quad 117,123-126,128,150)\end{array}$ & $3(85,127,128)$ \\
\hline
\end{tabular}

CBD, cannabidiol; NA, not available (not investigated).

${ }^{a}$ The prevalence of studies focused on acute vs. chronic effects is unequal, as is the focus on individual cognitive domains; strength metrics are based on qualitative interpretation of the literature, subjectively weighed on greater or lesser evidence for impairment across the published studies, considering the number of studies conducted and their quality (e.g., design, sample size), reached by consensus between the authors of this review.

$b_{+++}$, strong and largely consistent evidence for impairment; ++ , moderate evidence for impairment; + , weak evidence for impairment, being based on only a small number of studies; +- , mixed evidence; -, little or no evidence for impairment. 
exceptions $(53,54)]$ and even in only occasional users (55). Significant associations between poorer performance in regular users and frequency, quantity, duration, and age of onset of cannabis use have been reported (47,49,56-58). Consistent with previous findings (59), long-term users appear to be more affected than short-term users $(60,61)$. One study reported greater impairment associated with higher THC compared with CBD exposure (62). Improvement (63) or recovery $(55,57$, 64-66) with abstinence has been observed in some studies or indices, but not others $(64,65,67)$ (see Supplement 1 and further on).

Working Memory. Whether working memory is impaired by cannabis is less clear, possibly because of the wide range of different working memory tasks employed. Acute administration of THC, dronabinol, or nabilone affected working memory inconsistently across Sternberg, delayed matching to sample, spatial or numeric working memory, $n$-back, digit recall, and digit span tasks (36-40,42,43,68-78). Similarly, chronic cannabis use was shown to impair working memory in young adults on immediate recall (79), verbal reasoning (80), and verbal $n$-back (81) working memory tasks, but not on spatial working memory $(48,82)$ or digit span $(52,53)$, whereas spatial working memory was impaired in adolescent users (46), suggestive of differential effects in the developing brain. In older users, two studies reported no impairment on letternumber sequence and spatial span tests of the Wechsler Memory Scale (83) or on an $n$-back task (84), whereas recent or heavy users were impaired on a range of Wechsler Adult Intelligence Scale working memory tasks, with greater frequency and quantity of use correlated with poorer performance (57). Impaired working memory persisted for a few weeks in some studies (65) but appears to mostly resolve with longer periods of abstinence $(35,55,57,67,85)$.

For other memory function, see Supplement 1.

\section{Attention}

Impaired attention has been considered a hallmark of the intoxicating effects of cannabis. Further evidence has accumulated in support of acute exposure to cannabinoids impairing focused, divided, or sustained attention, often in a dosedependent manner $(36,37,42,43,68,70,71,86-88)$. In cases where lesser impairments were observed, this may be due to the development of tolerance among daily users $(76,89,90)$. Previous evidence for deficits in attention after chronic cannabis exposure was mixed, but more recent studies provide some clarity. Numerous studies report impairment in adolescent and adult cannabis users with a wide range of exposure as well as former users abstinent for several weeks on measures of sustained and divided attention, processing speed, rapid visual information processing, visual search, tracking, trail making, and paced serial addition $(46,54,55,57,61,91-94)$. Users abstinent for 23 days remained impaired relative to control subjects despite improvements in sustained and divided attention with increasing abstinence (91) with poor attentional performance associated with younger age of onset in this study (91) and another study of adolescents abstinent for 30 days (95). However, no difference between abstinent former users and control subjects on broader measures of attention was also reported $(57,63,64,79,95)$. Therefore, cannabis-related attentional impairment may reflect residual effects that dissipate gradually as cannabinoids are cleared from the body (Supplement 1).

Attentional Bias. Greater attentional bias to cannabisrelated stimuli has been noted in chronic cannabis users (96-102) and during acute intoxication in individuals with lower $\mathrm{CBD} / \mathrm{THC}$ ratios in hair (102). There are no studies of abstinent users after cessation of use, which may be a particularly important target for future research to strengthen the efficacy of treatment programs aimed at maintaining abstinence.

\section{Psychomotor Function}

Finger tapping, critical tracking, choice reaction time tasks, and digit-symbol substitution tasks have been used to measure psychomotor function. In infrequent users, smoked or vaporized cannabis impaired critical tracking $(42,89,103,104)$, affected reaction time and motor control in a dose-dependent manner (70), and disrupted motor function in a task with a motivational component (105). In heavy users, high-dose smoked cannabis resulted in more collisions in a virtual maze task (106) but did not affect critical tracking $(89,90)$. Oral administration of THC [or IV (37)], nabilone, or dronabinol impaired psychomotor function in seven of eight studies $(37,43,68,74,76,77,107)$, with only one study finding no significant impairment (73). Findings regarding the chronic effects of cannabis on psychomotor function are mixed, being reported as impaired $(51,54,80,108)$, improved $(48)$, and unaffected $(46,78)$. Psychomotor function was impaired in users abstinent for $23-35$ days $(57,65,67,91)$, with a trend also after 12 months of abstinence (finger tapping) (64). The weight of evidence suggests that psychomotor function is affected by acute intoxication and that this likely persists for some time after chronic cannabis exposure.

\section{Executive Function}

Planning, Reasoning, Interference Control, and Problem Solving. On similar tasks of planning, reasoning, interference control, and problem solving, THC administration was found to impair performance in some studies $(38,41,103$, $104,106,109)$, but not others $(39,86,89)$, equally across samples of occasional, moderate, and heavy users. Impaired performance may depend on extent of prior exposure, route of administration, dose delivered, and blood cannabinoid concentrations at baseline and after dosing (89). With regard to the chronic effects of cannabis, numerous studies reported null findings in case-control comparisons $(46,54,66,81,95,98$, $110,111)$, whereas several others found cannabis-related deficits in heavy users $(53,78,83,112)$, including adolescents (113), early-onset but not late-onset adult users (114), and older users (57), and associated with persistent use in a longitudinal study (60). Impaired executive function was evident despite intact performance on other cognitive tasks $(48,82)$ and associated with self-reported problems related to cannabis use (115). Studies in which executive dysfunction was detected tended 
to have older samples than the studies in which no impairments were observed, which included predominantly adolescent and young adult users. It may be that executive dysfunction becomes more evident beyond the period of maturation of the frontal lobes, perhaps reflecting perturbed neurodevelopment. Consistent with this interpretation, three abstinence studies reported no group differences relative to control subjects in younger samples $(65,85,95)$, whereas persistent executive dysfunction was observed in users abstinent for $\geq 28$ days aged $\sim 35-50$ years (57) and in users abstinent for 12 months aged 38-51 years (64), where impaired performance on block design tests was the only significant difference detected between abstinent users and their nonuser twins. Older users have also been exposed to far more cannabis use over the lifetime.

Inhibition. Measures of inhibition are derived from paradigms such as go/no-go or stop-signal reaction time tasks. Acute administration of THC has consistently been reported to increase stop-signal reaction time in both occasional and heavier cannabis users $(42,89,104,109)$. Findings in chronic users are more mixed $(45,50,54,56,82,116-118)$ (Supplement 1$)$.

Verbal Fluency. Three studies reported no effect on verbal fluency during acute intoxication with THC or cannabis $(36,38,44)$, but there has been little consistency regarding chronic or abstinence effects $(44,48,51,53,54,61,65,67,85$, $93,110,119)$ (Supplement 1). The findings suggest that if verbal fluency is impaired in cannabis users, it is more likely to be in older individuals with longer durations of exposure, whereas in younger users, impairment in verbal fluency may depend on intellectual functioning and on the task employed.

Time Estimation. The subjective effect of cannabis distorting time is well known, but objective evidence from new studies of time estimation is limited (Supplement 1).

In summary, executive function subdomains are differentially affected by acute administration and chronic exposure to cannabis. There are clear acutely impairing effects on inhibition, whereas planning, problem solving, reasoning, and interference control are inconsistently impaired, and the moderators of impaired performance require further investigation. The latter subdomains may be more affected in older chronic users or with greater exposure to cannabis. Literature assessing recovery of executive functions with abstinence is very sparse, and this is an important area for optimizing treatment programs for cannabis dependence. For example, one study found that poor neurocognitive performance was associated with relapse to cannabis use at 1-year follow-up in adolescents (95).

\section{Decision Making, Reward Processing, and Delay Discounting}

Measures of risky and impulsive decision making include performance on the lowa Gambling Task, delay discounting tasks, and behavioral risk-taking tasks. Some studies found that acute administration of THC adversely affected decision making by altering sensitivity to reward and punishment and increasing risk taking in infrequent (120) and regular users $(106,121,122)$, but not all studies found impaired decision making $(103,109)$. Evidence for effects of chronic cannabis use on decision-making is mixed. Although several studies reported poorer decision-making performance across a range of tasks $(48,78,82,117,123,124)$, especially decreased sensitivity to loss and greater sensitivity to gains (123), clear group differences were not found in other studies $(45,50,94,125-127)$. Cognitive flexibility in decision making is also affected by chronic cannabis exposure $(45,113,116)$. Behavioral risk taking was greater in adolescents with a mean period of abstinence of 53 days (85) and associated with extent of prior exposure in users with an abstinence period of 25 days (127), but was unaffected in other studies of current users $(50,56,125)$. No delay discounting performance differences were found between current and abstinent users and control subjects (128). Thus, risky decision making and sensitivity to reward are increased during acute intoxication. Despite a large number of studies of chronic users in the past decade, the extent to which these effects persist in chronic or abstinent users remains unclear.

\section{DISCUSSION}

In general, the literature on the cognitive effects of cannabis exposure continues to be plagued with complexity in terms of heterogeneity of both the extent of cannabis exposure in the samples assessed and the means of assessing cognitive function (18-21). The nature of the samples recruited and the way in which prior exposure to cannabis is quantified affect interpretation of findings for acute and chronic effects. In studies of chronic users, associations with frequency of use are more likely to reflect the residual effects of acute or subchronic intoxication, associations with dose of exposure may reflect residual or cumulative effects, and associations with the duration of use are likely to indicate more persistent cannabis-related alterations (20). These parameters may also interact with the neurodevelopmental period during which regular cannabis use is started, and increasing consideration has been given to age of onset effects and assessing adolescent users. Potential sex differences are insufficiently addressed in studies of predominantly male cannabis users ( $\sim 75 \%$ of studies reviewed), although many argue that this overrepresentation matches the sex distribution of cannabis users in the general population (129). Where sex effects were tested ( $\sim 12 \%$ of studies), very few were found (see Supplements 1 and 2). Evidence for sex differences in cannabinoid metabolism, action, and brain morphology in cannabis users (130-132) suggests that future research should further investigate these differences in relation to cognition, both following acute administration and with chronic exposure. Several key issues are critical to consider further.

\section{Dose, Route of Administration, and Tolerance Effects}

Acute administration studies often, but inconsistently, report dose-dependent effects (Supplements 1 and 2 contain further details of doses administered). Discrepancies may be due to differing routes of administration, with IV, smoked, and vaporized cannabinoids exerting more immediate but 
shorter-lasting effects than effects following oral or sublingual administration. The duration of impaired cognition after acute administration has not been further investigated; most studies conducted a single assessment immediately after or within 2-3 hours of dosing. The development of tolerance is often assumed to occur in frequent or dependent users and is inferred to explain modest effects in some studies, with supportive reference to preclinical literature and some prior, but limited, human studies. Most studies of acute administration examined effects in a single sample of control subjects or occasional or infrequent users (23 studies), or a single sample of regular, frequent, or daily users (11 studies), whereas only 4 studies directly compared effects in cannabis users versus control subjects (2 studies; 37,87 ) or in frequent versus infrequent users (2 studies; 89,149) (Supplement 2). These latter studies reported blunted impairing effects in regular or frequent users of acute smoked cannabis on critical tracking and divided attention or of IV THC on spatial working memory, verbal memory (inconsistently), and time estimation. Tolerance may occur in other cognitive domains, but the research over the past decade has not significantly advanced knowledge of tolerance effects beyond the limited previous evidence in humans (87). Although cognitive impairment after acute cannabinoid exposure may be blunted in regular users, substantial further evidence has accumulated that it nevertheless still exists across multiple domains (psychomotor, attention, and, inconsistently, memory) and with potential real-world effects on complex tasks involving these domains, such as driving (133).

\section{Specificity to Cannabis and Potential Confounds}

The literature continues to be riddled with a range of potential confounds that may affect specific attribution of impairment to cannabinoids, including largely premorbid functionality and other substance use. The strongest design to address these is a large-sample prospective study that controls for cognitive ability assessed before initiation of cannabis use, years of education, and other substance use. One such study examined neuropsychological change from childhood to age 38 and found that persistent cannabis use or dependence was associated with an IQ decline of $\sim 6$ points; this reflected broad decline in functioning not specific to any particular cognitive domain; cessation of use did not restore IQ in adolescent-onset users; and specificity to persistent cannabis use was determined by ruling out effects caused by recent cannabis use and persistent tobacco, alcohol, or other drug use (60). Two further studies controlling for premorbid function showed that adolescent cannabis users showed impaired verbal learning and memory (47) and immediate and delayed memory and processing speed (79), whereas former users did not differ from control subjects (79). Numerous studies have not controlled for premorbid functioning or ascertained current intellectual functioning; $>50 \%$ of studies did not report IQ or years of education. Where groups were matched on IQ or IQ was controlled for in analyses, persistent impairments to cognition were identified for immediate and delayed memory (79), verbal learning and memory $(39,61)$, verbal fluency, attention, and executive function (61) [although not in other studies $(84,128)$ ].

Alcohol and tobacco use as well as other illicit substance use are common in cannabis users, and a disconcerting number of studies continue to fail to report or account for this (Supplements 1 and 2). Means of dealing with these potential confounds include applying a heterogeneous range of exclusion criteria, often poorly specified; matching comparison groups on levels of use; and covarying for other substance use but with wide-ranging metrics (e.g., quantity/ frequency measures, lifetime use, dependence/abuse scores). Mostly, the cognitively impairing effects of chronic cannabis use have held after controlling for other substance use, but not in all studies (Supplement 1). Greater standardization of not only cannabis use metrics across studies but also tobacco, alcohol, and other drug use would enable better characterization of the specificity of cannabis effects. Further research to examine additive, interactive, or synergistic effects of cannabinoids with other substances is required.

\section{Persistence or Recovery of Function With Abstinence}

Recovery of function after prolonged abstinence remains contentious. The persistence of impairments or recovery of cognitive function after a period of abstinence $>24$ hours, most often for several weeks (21-35 days; only a few went beyond this period) was examined in 18 new studies. In 11 studies, crosssectional comparisons were performed of former users (abstinent 7 days to $>1$ year) and current users or nonuser control subjects; 9 of these studies assessed adolescents or young adults. Seven were prospective studies, assessing cannabis users at baseline and at follow-up (with some intervening measures) over periods ranging from 21 days to 4-8 years of abstinence. Although this is a stronger design, there remains a conspicuous paucity of these studies, as two were confounded by concomitant pharmacologic treatments $(63,93)$.

Cross-sectional studies report persistent impairing effects on some aspects of attention, verbal and working memory, and psychomotor speed in adolescents abstinent for 28 days (65) and 35 days (67), but not on other aspects of these and other cognitive domains. Poor performance was associated with lifetime cannabis exposure (65) or an earlier age of use onset in adolescents with 30 days of abstinence (95) and predicted relapse to cannabis use during a 1-year follow-up (95). Even after 53 days of abstinence, adolescents showed impaired working memory and risk taking (85). Young adults abstinent for up to 4 weeks showed poorer verbal fluency relative to control subjects (119) and nonsignificantly poorer performance on a gambling task, associated with prior quantity of weekly cannabis use (127). Older adults abstinent for $>28$ days were impaired on executive function and information processing but not attention and working memory (57). Lyons et al. (64) argued that their study of monozygotic twins, discordant for cannabis use with $>12$ months abstinence, provides evidence against long-term effects of cannabis on cognition, despite finding impaired performance on block design tests and trends toward poorer long delay and cued verbal recall and poorer finger tapping performance in the former users. Such studies offer a rare opportunity to control for underlying vulnerability to cannabis use, which may nevertheless interact with effects of persistent use.

In the prospective studies, only two controlled for premorbid function; one found that adolescent former users did not 
Table 2. Key Findings for Cognitive Impairment in Cannabis Users

\begin{tabular}{l}
\hline Acute Effects of Cannabis on Cognition \\
\hline Impaired verbal learning and memory \\
\hline Impaired working memory and other memory functions \\
\hline Impaired attention, task and dose dependent \\
\hline Impaired inhibition, less so for other executive functions \\
\hline Impaired psychomotor function \\
\hline Chronic Effects of Cannabis on Cognition \\
\hline Impaired verbal learning and memory \\
\hline Impaired attention and attentional bias \\
\hline Possible impaired psychomotor function \\
\hline Mixed evidence for executive function and decision making \\
\hline Most associated with cannabis use parameters, particularly frequency \\
of use and age of onset \\
\hline Recovery of Function With Abstinence \\
\hline Likely persistent effects on attention and psychomotor function \\
\hline Possible persistent effects on verbal learning and memory \\
\hline Evidence insufficient and mixed
\end{tabular}

differ from control subjects on any cognitive measures (79), whereas another large and well-controlled prospective study showed that cannabis use before the age of 18 resulted in greater decline in IQ by age 38 persisting even after cessation or reduction of use in the past year (60). Poor verbal learning improved in adolescents by 2 weeks of abstinence, but visual search remained impaired at 3 weeks relative to baseline (55). An adult sample showed improvements in critical tracking and divided attention with increasing abstinence periods over 8-23 days, but the sample subjects remained impaired relative to control subjects; withdrawal and age of onset effects were observed (91). In a large prospective study following a sample across three waves of data collection spaced 4 years apart, former heavy users abstinent for $\geq 12$ months improved relative to ongoing heavy users on immediate verbal memory and did not differ from nonusers on any cognitive measure (66).

Given the plasticity of the human brain, recovery of function might be anticipated, and consistent with previous findings $(134,135)$, the evidence from some (but not all) of these recent studies suggests that verbal learning and memory impairment may recover with prolonged abstinence. Yet evidence for persistent cognitive dysfunction continues to emerge. Neither the precise cannabis use metrics required for the persistence of cognitive deficits nor the neural mechanisms underlying the persistence of deficits have been elucidated. The latter likely include neurotransmitter system dysfunction (136-138) and regional brain structural and connectivity alterations $(32,139)$, which may take significant time to be restored to pre-cannabis use integrity and functionality [however, see Yücel et al. (140)]. Previous studies using sensitive measures of brain function detected duration of exposure-related impaired attentional processes in 2-year abstinent users (141). Further well-controlled prospective studies monitoring restoration of brain function and structure from current use through cessation of use and over prolonged abstinence are urgently needed.

\section{CONCLUSIONS}

Further significant evidence has emerged supporting the finding that acute and chronic exposure to cannabinoids impairs cognition, especially in the domains of verbal learning, memory, and attention (Table 2). Mixed evidence across the range of other cognitive domains is likely due to ongoing heterogeneity in the cognitive tests employed, prior cannabis use histories, and the assessment of cannabis use metrics as well as the neurodevelopmental stage at both onset and cessation of cannabis use. Nevertheless, it is clear from the literature reviewed that cognitive impairment on a range of domains can persist beyond the period of acute intoxication and potentially affect daily functioning in cannabis users and hence the range of adverse educational and other psychosocial outcomes identified as associated with frequent use, in particular for adolescent users (17). Multiple potential moderators of cannabinoid effects remain underinvestigated, including premorbid and other individual differences, genetic factors, sex, psychopathology, and polydrug use, and few studies consider the range of compounds in cannabis that interactively moderate the effects of THC, despite increasing interest in CBD. Further prospective and mechanistic studies are required to understand the impact of cannabinoids during brain maturation in adolescence through young adulthood and interacting with normal and abnormal aging processes in later years. The time course and moderators of potential recovery of cognitive function necessitate more precise delineation. In light of increasing trends toward legalization or medicalization of cannabis, it is imperative to research further the parameters of cannabis use that result in impairment and the potential for protection from cognitive harm by CBD (evidence is growing but is not definitive) such that harm minimization strategies may be implemented, and to understand the therapeutic parameters of any of the cannabinoids to enable the benefits of medications without concomitant brain and cognitive harm.

\section{ACKNOWLEDGMENTS AND DISCLOSURES}

This work was supported by the Australian Research Council Future Fellowship Grant No. FT110100752 (to NS) and National Health and Medical Research Council Project Grant No. 1007593 (to NS) and Senior Research Fellowship Grant No. 1021973 (to MY).

We thank Madeleine Godber for assistance with literature searches and document retrieval.

The authors report no biomedical financial interests or potential conflicts of interest.

\section{ARTICLE INFORMATION}

From the School of Psychology and Illawarra Health and Medical Research Institute (SJB, $\mathrm{HHvH}, \mathrm{CB}, \mathrm{NS}$ ), University of Wollongong, Wollongong; and Brain and Mental Health Laboratory (MY), Monash Institute of Cognitive and Clinical Neurosciences, School of Psychological Sciences, Monash University, Melbourne, Australia.

$\mathrm{SJB}, \mathrm{HHvH}$, and NS contributed equally to this work.

Address correspondence to Nadia Solowij, Ph.D., School of Psychology, University of Wollongong, Northfields Avenue, Wollongong, NSW 2522, Australia; E-mail: nadia@uow.edu.au.

Received Apr 2, 2015; revised Nov 11, 2015; accepted Dec 1, 2015.

Supplementary material cited in this article is available online at http:// dx.doi.org/10.1016/j.biopsych.2015.12.002. 


\section{REFERENCES}

1. AlHW (2013): National Drug Strategy Household Survey. Canberra: Australian Institute of Health and Welfare.

2. UNDOC (2014): World Drug Report 2014. Vienna: United Nations Office on Drugs and Crime.

3. Volkow ND, Compton WM, Weiss SR (2014): Adverse health effects of marijuana use. N Engl J Med 371:879.

4. Hall W, Degenhardt $L$ (2014): The adverse health effects of chronic cannabis use. Drug Test Anal 6:39-45.

5. Batalla A, Bhattacharyya S, Yücel M, Fusar-Poli P, Crippa JA, Nogue S, et al. (2013): Structural and functional imaging studies in chronic cannabis users: A systematic review of adolescent and adult findings. PLoS One 8:e55821.

6. Lorenzetti V, Lubman DI, Whittle S, Solowij N, Yücel M (2010): Structural MRI findings in long-term cannabis users: What do we know? Subst Use Misuse 45:1787-1808.

7. Lorenzetti V, Solowij N, Fornito A, Lubman DI, Yucel M (2014): The association between regular cannabis exposure and alterations of human brain morphology: An updated review of the literature. Curr Pharm Des 20:2138-2167.

8. James A, James C, Thwaites T (2013): The brain effects of cannabis in healthy adolescents and in adolescents with schizophrenia: A systematic review. Psychiatry Res 214:181-189

9. Bossong MG, Jager G, Bhattacharyya S, Allen P (2014): Acute and non-acute effects of cannabis on human memory function: A critical review of neuroimaging studies. Curr Pharm Des 20: 2114-2125.

10. Bhattacharyya S, Crippa JA, Martin-Santos R, Winton-Brown T, Fusar-Poli P (2009): Imaging the neural effects of cannabinoids: Current status and future opportunities for psychopharmacology. Curr Pharm Des 15:2603-2614.

11. Martin-Santos R, Fagundo AB, Crippa JA, Atakan Z, Bhattacharyya S, Allen P, et al. (2010): Neuroimaging in cannabis use: A systematic review of the literature. Psychol Med 40:383-398.

12. Moore TH, Zammit S, Lingford-Hughes A, Barnes TR, Jones PB, Burke M, et al. (2007): Cannabis use and risk of psychotic or affective mental health outcomes: A systematic review. Lancet 370: 319-328.

13. Di Forti M, Marconi A, Carra E, Fraietta S, Trotta A, Bonomo M, et al. (2015): Proportion of patients in south London with first-episode psychosis attributable to use of high potency cannabis: A casecontrol study. Lancet Psychiatry 2:233-238.

14. Gibbs M, Winsper C, Marwaha S, Gilbert E, Broome M, Singh SP (2015): Cannabis use and mania symptoms: A systematic review and meta-analysis. J Affect Disord 171:39-47.

15. Radhakrishnan R, Wilkinson ST, D'Souza DC (2014): Gone to pot-a review of the association between cannabis and psychosis. Front Psychiatry 5:54.

16. Chadwick B, Miller ML, Hurd YL (2013): Cannabis use during adolescent development: Susceptibility to psychiatric illness. Front Psychiatry 4:129.

17. Silins E, Horwood LJ, Patton GC, Fergusson DM, Olsson CA, Hutchinson DM, et al. (2014): Young adult sequelae of adolescent cannabis use: An integrative analysis. Lancet Psychiatry1: 286-293.

18. Solowij N, Battisti R (2008): The chronic effects of cannabis on memory in humans: A review. Curr Drug Abuse Rev 1:81-98.

19. Solowij N, Michie PT (2007): Cannabis and cognitive dysfunction: Parallels with endophenotypes of schizophrenia? J Psychiatry Neurosci 32:30-52

20. Solowij N, Pesa N (2010): Cognitive abnormalities and cannabis use. Rev Bras Psiquiatria 32:S31-S40.

21. Solowij N, Pesa N (2012): Cannabis and cognition: Short and longterm effects. In: Castle D, Murray R, D'Souza DC, editors. Marijuana and Madness, 2nd ed. Cambridge: Cambridge University Press, 91-102.

22. Crean RD, Crane NA, Mason BJ (2011): An evidence based review of acute and long-term effects of cannabis use on executive cognitive functions. J Addict Med 5:1-8.
23. Burns HD, Van Laere K, Sanabria-Bohórquez S, Hamill TG, Bormans G, Eng W-S, et al. (2007): [18F]MK-9470, a positron emission tomography (PET) tracer for in vivo human PET brain imaging of the cannabinoid-1 receptor. Proc Natl Acad Sci U S A 104: 9800-9805.

24. Lubman DI, Cheetham A, Yücel M (2015): Cannabis and adolescent brain development. Pharmacol Ther 148c:1-16.

25. Arseneault L, Cannon M, Poulton R, Murray R, Caspi A, Moffitt TE (2002): Cannabis use in adolescence and risk for adult psychosis: Longitudinal prospective study. BMJ 325:1212-1213.

26. Fergusson DM, Horwood LJ, Swain-Campbell NR (2003): Cannabis dependence and psychotic symptoms in young people. Psychol Med 33:15-21

27. van Os J, Bak M, Hanssen M, Bijl RV, de Graaf R, Verdoux H (2002): Cannabis use and psychosis: A longitudinal population-based study. Am J Epidemiol 156:319-327.

28. Zammit S, Allebeck P, Andreasson S, Lundberg I, Lewis G (2002): Self reported cannabis use as a risk factor for schizophrenia in Swedish conscripts of 1969: Historical cohort study. BMJ 325:1199.

29. Leweke FM, Gerth CW, Klosterkotter J (2004): Cannabis-associated psychosis: Current status of research. CNS Drugs 18:895-910.

30. Bhattacharyya S, Morrison PD, Fusar-Poli P, Martin-Santos R, Borgwardt S, Winton-Brown T, et al. (2010): Opposite effects of delta-9-tetrahydrocannabinol and cannabidiol on human brain function and psychopathology. Neuropsychopharmacology 35:764-774

31. Batalla A, Crippa JA, Busatto GF, Guimaraes FS, Zuardi AW, Valverde O, et al. (2014): Neuroimaging studies of acute effects of THC and CBD in humans and animals: A systematic review. Curr Pharm Des 20:2168-2185.

32. Lorenzetti V, Solowij N, Yücel M (2016): The role of cannabinoids on neuroanatomical alterations in cannabis users. Biol Psychiatry 79: e17-e31.

33. Moher D, Liberati A, Tetzlaff J, Altman DG, The PRISMA Group (2009): Preferred reporting items for systematic reviews and metaanalyses: The PRISMA statement. PLoS Med 6:e1000097.

34. Fletcher PC, Honey GD (2006): Schizophrenia, ketamine and cannabis: Evidence of overlapping memory deficits. Trends Cogn Sci 10:167-174.

35. Ranganathan M, D'Souza D (2006): The acute effects of cannabinoids on memory in humans: A review. Psychopharmacology 188: 425-444

36. D'Souza DC, Perry E, MacDougall L, Ammerman Y, Cooper T, Wu YT, et al. (2004): The psychotomimetic effects of intravenous delta9-tetrahydrocannabinol in healthy individuals: Implications for psychosis. Neuropsychopharmacology 29:1558-1572.

37. D'Souza DC, Braley G, Blaise R, Vendetti M, Oliver S, Pittman B, et al (2008): Effects of haloperidol on the behavioral, subjective, cognitive, motor, and neuroendocrine effects of Delta-9-tetrahydrocannabinol in humans. Psychopharmacology 198:587-603.

38. Morrison PD, Zois V, McKeown DA, Lee TD, Holt DW, Powell JF et al. (2009): The acute effects of synthetic intravenous delta-9tetrahydrocannabinol on psychosis, mood and cognitive functioning. Psychol Med 39:1607-1616.

39. Ranganathan M, Carbuto M, Braley G, Elander J, Perry E, Pittman B, et al. (2012): Naltrexone does not attenuate the effects of intravenous delta-9-tetrahydrocannabinol in healthy humans. Int $\mathrm{J} \mathrm{Neu}$ ropsychopharmacol 15:1251-1264.

40. Englund A, Morrison PD, Nottage J, Hague D, Kane F, Bonaccorso S, et al. (2013): Cannabidiol inhibits THC-elicited paranoid symptoms and hippocampal-dependent memory impairment. J Psychopharmacol 27:19-27.

41. Liem-Moolenaar M, te Beek ET, de Kam ML, Franson KL, Kahn RS, Hijman R, et al. (2010): Central nervous system effects of haloperidol on THC in healthy male volunteers. J Psychopharmacol 24: 1697-1708.

42. Theunissen EL, Heckman P, de Sousa Fernandes Perna EB, Kuypers KP, Sambeth A, Blokland A, et al. (2015): Rivastigmine but not vardenafil reverses cannabis-induced impairment of verbal memory in healthy humans. Psychopharmacology 232:343-353. 
43. Wesnes KA, Annas P, Edgar CJ, Deeprose C, Karlsten R, Philipp A, et al. (2010): Nabilone produces marked impairments to cognitive function and changes in subjective state in healthy volunteers. J Psychopharmacol 24:1659-1669.

44. Morgan CJ, Schafer G, Freeman TP, Curran HV (2010): Impact of cannabidiol on the acute memory and psychotomimetic effects of smoked cannabis: Naturalistic study: Naturalistic study [corrected]. Br J Psychiatry 197:285-290.

45. Dougherty DM, Mathias CW, Dawes MA, Furr RM, Charles NE, Liguori A, et al. (2013): Impulsivity, attention, memory, and decisionmaking among adolescent marijuana users. Psychopharmacology 226:307-319.

46. Harvey MA, Sellman JD, Porter RJ, Frampton CM (2007): The relationship between non-acute adolescent cannabis use and cognition. Drug Alcohol Rev 26:309-319.

47. Solowij N, Jones KA, Rozman ME, Davis SM, Ciarrochi J, Heaven PC, et al. (2011): Verbal learning and memory in adolescent cannabis users, alcohol users and non-users. Psychopharmacology 216: 131-144.

48. Becker MP, Collins PF, Luciana M (2014): Neurocognition in collegeaged daily marijuana users. J Clin Exp Neuropsychol 36:379-398.

49. Cuttler C, McLaughlin RJ, Graf P (2012): Mechanisms underlying the link between cannabis use and prospective memory. PLoS One 7: e36820.

50. Gonzalez R, Schuster RM, Mermelstein RJ, Vassileva J, Martin EM, Diviak KR (2012): Performance of young adult cannabis users on neurocognitive measures of impulsive behavior and their relationship to symptoms of cannabis use disorders. J Clin Exp Neuropsychol 34:962-976.

51. Looby A, Earleywine M (2010): Gender moderates the impact of stereotype threat on cognitive function in cannabis users. Addict Behav 35:834-839.

52. Macher RB, Earleywine M (2012): Enhancing neuropsychological performance in chronic cannabis users: The role of motivation. J Clin Exp Neuropsychol 34:405-415.

53. Gruber SA, Sagar KA, Dahlgren MK, Racine M, Lukas SE (2012): Age of onset of marijuana use and executive function. Psychol Addict Behav 26:496-506.

54. Lisdahl KM, Price JS (2012): Increased marijuana use and gender predict poorer cognitive functioning in adolescents and emerging adults. J Int Neuropsychol Soc 18:678-688.

55. Hanson KL, Winward JL, Schweinsburg AD, Medina KL, Brown SA, Tapert SF (2010): Longitudinal study of cognition among adolescent marijuana users over three weeks of abstinence. Addict Behav 35: 970-976.

56. Crane NA, Schuster RM, Gonzalez R (2013): Preliminary evidence for a sex-specific relationship between amount of cannabis use and neurocognitive performance in young adult cannabis users. J Int Neuropsychol Soc 19:1009-1015

57. Thames AD, Arbid N, Sayegh P (2014): Cannabis use and neurocognitive functioning in a non-clinical sample of users. Addict Behav 39:994-999.

58. Wagner D, Becker B, Gouzoulis-Mayfrank E, Daumann J (2010): Interactions between specific parameters of cannabis use and verbal memory. Prog Neuropsychopharmacol Biol Psychiatry 34:871-876.

59. Solowij N, Stephens RS, Roffman RA, Babor T, Kadden R, Miller M, et al. (2002): Cognitive functioning of long term heavy cannabis users seeking treatment. JAMA 287:1123-1131.

60. Meier MH, Caspi A, Ambler A, Harrington H, Houts R, Keefe RS, et al. (2012): Persistent cannabis users show neuropsychological decline from childhood to midlife. Proc Natl Acad Sci U S A 109: E2657-E2664.

61. Messinis L, Kyprianidou A, Malefaki S, Papathanasopoulos P (2006): Neuropsychological deficits in long-term frequent cannabis users. Neurology 66:737-739.

62. Morgan CJ, Gardener C, Schafer G, Swan S, Demarchi C, Freeman TP, et al. (2012): Sub-chronic impact of cannabinoids in street cannabis on cognition, psychotic-like symptoms and psychological well-being. Psychol Med 42:391-400.
63. Roten A, Baker NL, Gray KM (2015): Cognitive performance in a placebo-controlled pharmacotherapy trial for youth with marijuana dependence. Addict Behav 45:119-123.

64. Lyons MJ, Bar JL, Panizzon MS, Toomey R, Eisen S, Xian H, et al. (2004): Neuropsychological consequences of regular marijuana use: a twin study. Psychol Med 34:1239-1250.

65. Medina KL, Hanson KL, Schweinsburf AD, Cohen-Zion M, Nafel BJ, Tapert SF (2007): Neuropsychological functioning in adolescent marijuana users: Subtle deficits detectable after a month of abstinence. J Int Neuropsychol Soc 13:807-820.

66. Tait RJ, Mackinnon A, Christensen H (2011): Cannabis use and cognitive function: 8-year trajectory in a young adult cohort. Addiction 106:2195-2203.

67. Winward JL, Hanson KL, Tapert SF, Brown SA (2014): Heavy alcoho use, marijuana use, and concomitant use by adolescents are associated with unique and shared cognitive decrements. J Int Neuropsychol Soc 20:784-795.

68. Bedi G, Cooper ZD, Haney M (2013): Subjective, cognitive and cardiovascular dose-effect profile of nabilone and dronabinol in marijuana smokers. Addict Biol 18:872-881.

69. Freeman D, Dunn G, Murray RM, Evans N, Lister R, Antley A, et al. (2015): How cannabis causes paranoia: Using the intravenous administration of $\Delta^{9}$-tetrahydrocannabinol (THC) to identify key cognitive mechanisms leading to paranoia. Schizophr Bull 41: 391-399.

70. Hunault CC, Mensinga TT, Bocker KB, Schipper CM, Kruidenier M, Leenders ME, et al. (2009): Cognitive and psychomotor effects in males after smoking a combination of tobacco and cannabis containing up to $69 \mathrm{mg}$ delta-9-tetrahydrocannabinol (THC). Psychopharmacology 204:85-94.

71. Kollins SH, Schoenfelder EN, English JS, Holdaway A, Van Voorhees E, O'Brien BR, et al. (2015): An exploratory study of the combined effects of orally administered methylphenidate and delta-9tetrahydrocannabinol (THC) on cardiovascular function, subjective effects, and performance in healthy adults. J Subst Abuse Treat 48 96-103.

72. Lane SD, Cherek DR, Lieving LM, Tcheremissine OV (2005): Marijuana effects on human forgetting functions. J Exp Anal Behav 83:67-83.

73. Lile JA, Kelly TH, Hays LR (2011): Separate and combined effects of the cannabinoid agonists nabilone and delta(9)-THC in humans discriminating delta(9)-THC. Drug Alcohol Depend 116:86-92.

74. Lile JA, Kelly TH, Hays LR (2014): Separate and combined effects of the GABA-A positive allosteric modulator diazepam and delta(9)THC in humans discriminating delta(9)-THC. Drug Alcohol Depend 143:141-148

75. Makela P, Wakeley J, Gijsman H, Robson PJ, Bhagwagar Z, Rogers RD (2006): Low doses of $\Delta-9$ tetrahydrocannabinol (THC) have divergent effects on short-term spatial memory in young, healthy adults. Neuropsychopharmacology 31:462-470.

76. Ramesh D, Haney M, Cooper ZD (2013): Marijuana's dosedependent effects in daily marijuana smokers. Exp Clin Psychopharmacol 21:287-293

77. Vandrey R, Stitzer ML, Mintzer MZ, Huestis MA, Murray JA, Lee D (2013): The dose effects of short-term dronabinol (oral THC) maintenance in daily cannabis users. Drug Alcohol Depend 128:64-70.

78. Whitlow CT, Liguori A, Brooke Livengood L, Hart SL, MussatWhitlow BJ, Lamborn CM, et al. (2004): Long-term heavy marijuana users make costly decisions on a gambling task. Drug Alcohol Depend 76:107-111.

79. Fried PA, Watkinson B, Gray R (2005): Neurocognitive consequences of marihuana-a comparison with pre-drug performance. Neurotoxicol Teratol 27:231-239.

80. Wadsworth EJ, Moss SC, Simpson SA, Smith AP (2006): Cannabis use, cognitive performance and mood in a sample of workers. J Psychopharmacol 20:14-23.

81. Herzig DA, Nutt D, Mohr C (2014): Alcohol and relatively pure cannabis use, but not schizotypy, are associated with cognitive attenuations. Front Psychiatry 5:133. 
82. Grant JE, Chamberlain SR, Schreiber L, Odlaug BL (2012): Neuropsychological deficits associated with cannabis use in young adults. Drug Alcohol Depend 121:159-162.

83. Scholes KE, Martin-Iverson MT (2010): Cannabis use and neuropsychological performance in healthy individuals and patients with schizophrenia. Psychol Med 40:1635-1646.

84. Verdejo-García A, Beatriz Fagundo A, Cuenca A, Rodriguez J, Cuyás E, Langohr K, et al. (2013): COMT val158met and 5-HTTLPR genetic polymorphisms moderate executive control in cannabis users. Neuropsychopharmacology 38:1598-1606.

85. Hanson KL, Thayer RE, Tapert SF (2014): Adolescent marijuana users have elevated risk-taking on the balloon analog risk task. J Psychopharmacol 28:1080-1087.

86. Anderson BM, Rizzo M, Block RI, Pearlson GD, O'Leary DS (2010): Sex, drugs, and cognition: Effects of marijuana. J Psychoactive Drugs 42:413-424.

87. D'Souza DC, Ranganathan M, Braley G, Gueorguieva R, Zimolo Z, Cooper T, et al. (2008): Blunted psychotomimetic and amnestic effects of delta-9-tetrahydrocannabinol in frequent users of cannabis. Neuropsychopharmacology 33:2505-2516.

88. Schoedel KA, Addy C, Chakraborty B, Rosko K, Dunbar S, Maes A, et al. (2012): Human abuse potential and cognitive effects of taranabant, a cannabinoid 1 receptor inverse agonist: A randomized, double-blind, placebo- and active-controlled, crossover study in recreational polydrug users. J Clin Psychopharmacol 32: 492-502.

89. Ramaekers JG, Kauert G, Theunissen EL, Toennes SW, Moeller MR (2009): Neurocognitive performance during acute THC intoxication in heavy and occasional cannabis users. J Psychopharmacol 23: 266-277.

90. Schwope DM, Bosker WM, Ramaekers JG, Gorelick DA, Huestis MA (2012): Psychomotor performance, subjective and physiological effects and whole blood Delta(9)-tetrahydrocannabinol concentrations in heavy, chronic cannabis smokers following acute smoked cannabis. J Anal Toxicol 36:405-412.

91. Bosker WM, Karschner EL, Lee D, Goodwin RS, Hirvonen J, Innis RB, et al. (2013): Psychomotor function in chronic daily Cannabis smokers during sustained abstinence. PLoS One 8:e53127.

92. Huijbregts SC, Griffith-Lendering MF, Vollebergh WA, Swaab $\mathrm{H}$ (2014): Neurocognitive moderation of associations between cannabis use and psychoneuroticism. J Clin Exp Neuropsychol 36: 794-805.

93. Mason BJ, Crean R, Goodell V, Light JM, Quello S, Shadan F, et al. (2012): A proof-of-concept randomized controlled study of gabapentin: Effects on cannabis use, withdrawal and executive function deficits in cannabis-dependent adults. Neuropsychopharmacology 37:1689-1698.

94. Shannon EE, Mathias CW, Dougherty DM, Liguori A (2010): Cognitive impairments in adolescent cannabis users are related to $\mathrm{THC}$ levels. Addict Dis Treat 9:158-163.

95. Hooper SR, Woolley D, De Bellis MD (2014): Intellectual, neurocognitive, and academic achievement in abstinent adolescents with cannabis use disorder. Psychopharmacology 231:1467-1477

96. Beraha EM, Cousijn J, Hermanides E, Goudriaan AE, Wiers RW (2013): Implicit associations and explicit expectancies toward cannabis in heavy cannabis users and controls. Front Psychiatry 4:59.

97. Cane JE, Sharma D, Albery IP (2009): The addiction Stroop task: Examining the fast and slow effects of smoking and marijuanarelated cues. J Psychopharmacol 23:510-519.

98. Cousijn J, Watson P, Koenders L, Vingerhoets WA, Goudriaan AE, Wiers RW (2013): Cannabis dependence, cognitive control and attentional bias for cannabis words. Addict Behav 38:2825-2832.

99. Field M (2005): Cannabis "dependence" and attentional bias for cannabis-related words. Behav Pharmacol 16:473-476.

100. Field M, Eastwood B, Bradley BP, Mogg K (2006): Selective processing of cannabis cues in regular cannabis users. Drug Alcohol Depend 85:75-82.

101. Field M, Mogg K, Bradley BP (2004): Cognitive bias and drug craving in recreational cannabis users. Drug Alcohol Depend 74:105-111.
102. Morgan CJ, Freeman TP, Schafer GL, Curran HV (2010): Cannabidiol attenuates the appetitive effects of Delta 9-tetrahydrocannabinol in humans smoking their chosen cannabis. Neuropsychopharmacology 35:1879-1885

103. Ramaekers JG, Kauert G, van Ruitenbeek P, Theunissen EL, Schneider E, Moeller MR (2006): High-potency marijuana impairs executive function and inhibitory motor control. Neuropsychopharmacology 31:2296-2303.

104. Ramaekers JG, Moeller MR, van Ruitenbeek P, Theunissen EL, Schneider E, Kauert G (2006): Cognition and motor control as a function of delta-9-THC concentration in serum and oral fluid: Limits of impairment. Drug Alcohol Depend 85:114-122.

105. Lane SD, Cherek DR, Pietras CJ, Tcheremissine OV (2004): Acute marijuana effects on response-reinforcer relations under multiple variable-interval schedules. Behav Pharmacol 15:305-309.

106. Weinstein A, Brickner O, Lerman H, Greemland M, Bloch M, Lester $\mathrm{H}$, et al. (2008): A study investigating the acute dose-response effects of $13 \mathrm{mg}$ and $17 \mathrm{mg}$ delta 9-tetrahydrocannabinol on cognitive-motor skills, subjective and autonomic measures in regular users of marijuana. J Psychopharmacol 22:441-451

107. Kaufmann RM, Kraft B, Frey R, Winkler D, Weiszenbichler S, Bäcker C, et al. (2010): Acute psychotropic effects of oral cannabis extract with a defined content of 89 -Tetrahydrocannabinol (THC) in healthy volunteers. Pharmacopsychiatry 43:24-32

108. Flavel SC, White JM, Todd G (2013): Abnormal maximal finger tapping in abstinent cannabis users. Hum Psychopharmacol 28 612-614.

109. Metrik J, Kahler CW, Reynolds B, McGeary JE, Monti PM, Haney M, et al. (2012): Balanced placebo design with marijuana: Pharmacological and expectancy effects on impulsivity and risk taking. Psychopharmacology 223:489-499.

110. Fisk JE, Montgomery C (2008): Real-world memory and executive processes in cannabis users and non-users. J Psychopharmacol 22 : 727-736.

111. Palermo L, Bianchini F, laria G, Tanzilli A, Guariglia C (2012): Assessing topographical orientation skills in cannabis users. Sci World J 2012:137071.

112. Fontes MA, Bolla KI, Cunha PJ, Almeida PP, Jungerman F, Laranjeira RR, et al. (2011): Frontal Assessment Battery (FAB) is a simple too for detecting executive deficits in chronic cannabis users. J Clin Exp Neuropsychol 33:523-531

113. Lane SD, Cherek DR, Tcheremissine OV, Steinberg JL, Sharon J (2007): Response perseveration and adaptation in heavy marijuanasmoking adolescents. Addict Behav 32:977-990.

114. Fontes MA, Bolla KI, Cunha PJ, Almeida PP, Jungerman F, Laranjeira RR, et al. (2011): Cannabis use before age 15 and subsequent executive functioning. Br J Psychiatry 198:442-447.

115. Day AM, Metrik J, Spillane NS, Kahler CW (2013): Working memory and impulsivity predict marijuana-related problems among frequent users. Drug Alcohol Depend 131:171-174.

116. Griffith-Lendering MF, Huijbregts SC, Vollebergh WA, Swaab H (2012): Motivational and cognitive inhibitory control in recreationa cannabis users. J Clin Exp Neuropsychol 34:688-697.

117. Moreno M, Estevez AF, Zaldivar F, Montes JM, Gutierrez-Ferre VE, Esteban L, et al. (2012): Impulsivity differences in recreational cannabis users and binge drinkers in a university population. Drug Alcohol Depend 124:355-362.

118. Vivas AB, Estevez AF, Moreno M, Panagis G, Flores P (2012): Use of cannabis enhances attentional inhibition. Hum Psychopharmacol 27: 464-469.

119. McHale S, Hunt N (2008): Executive function deficits in short-term abstinent cannabis users. Hum Psychopharmacol 23:409-415.

120. Rogers RD, Wakeley J, Robson PJ, Bhagwagar Z, Makela P (2007): The effects of low doses of delta-9 tetrahydrocannabinol on reinforcement processing in the risky decision-making of young healthy adults. Neuropsychopharmacology 32:417-428.

121. Lane SD, Cherek DR, Tcheremissine OV, Lieving LM, Pietras CJ (2005): Acute marijuana effects on human risk taking. Neuropsychopharmacology 30:800-809. 
122. Vadhan NP, Hart CL, van Gorp WG, Gunderson EW, Haney M, Foltin RW (2007): Acute effects of smoked marijuana on decision making, as assessed by a modified gambling task, in experienced marijuana users. J Clin Exp Neuropsychol 29:357-364.

123. Fridberg DJ, Queller S, Ahn WY, Kim W, Bishara AJ, Busemeyer JR, et al. (2010): Cognitive mechanisms underlying risky decision-making in chronic cannabis users. J Math Psychol 54:28-38.

124. Solowij N, Jones KA, Rozman ME, Davis SM, Ciarrochi J, Heaven PC, et al. (2012): Reflection impulsivity in adolescent cannabis users: A comparison with alcohol-using and non-substance-using adolescents. Psychopharmacology 219:575-586.

125. Gilman JM, Calderon V, Curran MT, Evins AE (2015): Young adult cannabis users report greater propensity for risk-taking only in nonmonetary domains. Drug Alcohol Depend 147:26-31.

126. Hermann D, Lemenager T, Gelbke J, Welzel H, Skopp G, Mann K (2009): Decision making of heavy cannabis users on the lowa Gambling Task: Stronger association with THC of hair analysis than with personality traits of the Tridimensional Personality Questionnaire. Eur Addict Res 15:94-98.

127. Verdejo-Garcia A, Benbrook A, Funderburk F, David P, Cadet JL, Bolla KI (2007): The differential relationship between cocaine use and marijuana use on decision-making performance over repeat testing with the lowa Gambling Task. Drug Alcohol Depend 90:2-11.

128. Johnson MW, Bickel WK, Baker F, Moore BA, Badger GJ, Budney AJ (2010): Delay discounting in current and former marijuana-dependent individuals. Exp Clin Psychopharmacol 18:99-107.

129. SAMHSA (2013): Results from the 2012 National Survey on Drug Use and Health: Summary of National Findings, NSDUH Series H-46, DHHS Publication No. SMA 13-4795. Rockville, MD: Substance Abuse and Mental Health Services Administration.

130. Fattore L, Fratta W (2010): How important are sex differences in cannabinoid action? Br J Pharmacol 160:544-548.

131. McQueeny T, Padula CB, Price J, Medina KL, Logan P, Tapert SF (2011): Gender effects on amygdala morphometry in adolescent marijuana users. Behav Brain Res 224:128-134.

132. Medina KL, McQueeny T, Nagel BJ, Hanson KL, Yang TT, Tapert SF (2009): Prefrontal cortex morphometry in abstinent adolescent marijuana users: Subtle gender effects. Addict Biol 14:457-468.

133. Hartman RL, Huestis MA (2013): Cannabis effects on driving skills. Clin Chem 59:478-492.

134. Pope HG Jr, Gruber AJ, Hudson JI, Huestis MA, Yurgelun-Todd D (2001): Neuropsychological performance in long-term cannabis users. Arch Gen Psychiatry 58:909-915.

135. Schreiner AM, Dunn ME (2012): Residual effects of cannabis use on neurocognitive performance after prolonged abstinence: A metaanalysis. Exp Clin Psychopharmacol 20:420-429.
136. Mechoulam R, Parker LA (2013): The endocannabinoid system and the brain. Annu Rev Psychol 64:21-47.

137. Castillo PE, Younts TJ, Chavez AE, Hashimotodani Y (2012): Endocannabinoid signaling and synaptic function. Neuron 76:487-492.

138. Fratta W, Fattore L (2013): Molecular mechanisms of cannabinoid addiction. Curr Opin Neurobiol 23:70-81.

139. Zalesky A, Solowij N, Yücel M, Lubman DI, Takagi M, Harding $\amalg$, et al. (2012): Effect of long-term cannabis use on axonal fibre connectivity. Brain 135:2245-2255.

140. Yücel M, Lorenzetti V, Suo C, Zalesky A, Fornito A, Takagi M, et al. (2016): Hippocampal harms, protection and recovery following regular cannabis use. Transl Psychiatry 6:e710. http://dx.doi.org/ 10.1038/tp.2015.201.

141. Solowij N (1995): Do cognitive impairments recover following cessation of cannabis use? Life Sci 56:2119-2126.

142. McClure EA, Lydiard JB, Goddard SD, Gray KM (2015): Objective and subjective memory ratings in cannabis-dependent adolescents. Am J Addict 24:47-52.

143. Schoedel KA, Chen N, Hilliard A, White L, Stott C, Russo E, et al. (2011): A randomized, double-blind, placebo-controlled, crossover study to evaluate the subjective abuse potential and cognitive effects of nabiximols oromucosal spray in subjects with a history of recreational cannabis use. Hum Psychopharmacol 26:224-236.

144. Morgan CJ, Rothwell E, Atkinson H, Mason O, Curran HV (2010): Hyper-priming in cannabis users: A naturalistic study of the effects of cannabis on semantic memory function. Psychiatry Res 176:213-218.

145. Bartholomew J, Holroyd S, Heffernan TM (2010): Does cannabis use affect prospective memory in young adults? J Psychopharmacol 24: 241-246.

146. Roser P, Gallinat J, Weinberg G, Juckel G, Gorynia I, Stadelmann AM (2009): Psychomotor performance in relation to acute oral administration of Delta9-tetrahydrocannabinol and standardized cannabis extract in healthy human subjects. Eur Arch Psychiatry Clin Neurosci 259:284-292.

147. Keen L, Turner AD (2014): Association between interleukin-6 and neurocognitive performance as a function of self-reported lifetime marijuana use in a community based sample of African American adults. J Int Neuropsychol Soc 20:773-783.

148. Lieving LM, Lane SD, Cherek DR, Tcheremissine OV (2006): Effects of marijuana on temporal discriminations in humans. Behav Pharmacol 17:173-183.

149. Sewell RA, Schnakenberg A, Elander J, Radhakrishnan R, Williams A, Skosnik PD, et al. (2013): Acute effects of THC on time perception in frequent and infrequent cannabis users. Psychopharmacology 226 : 401-413.

150. Martin-Soelch C, Kobel M, Stoecklin M, Michael T, Weber S, Krebs B, et al. (2009): Reduced response to reward in smokers and cannabis users. Neuropsychobiology 60:94-103. 